\title{
LEARNING FOR EMPLOYMENT - ANALYSIS OF THE COMPONENTS FORMING THE SUCCESSFUL PRODUCT INNOVATION IN ENTREPRENEURSHIP
}

Liga BRASLINA, Faculty of Business, Management and Economics, University of Latvia, Aspazijas blvd, 5, Riga, LV-1010, Latvia, liga.braslina@lu.lv (corresponding author)

Martins DANUSEVICS, Faculty of Business, Management and Economics, University of Latvia, Aspazijas blvd, 5, Riga, LV-1010, Latvia, martins.danusevics@lu.lv

Anda BATRAGA, Faculty of Business, Management and Economics, University of Latvia, Aspazijas blvd, 5, Riga, LV-1010, Latvia, anda.batraga@lu.lv

Aija LEGZDINA, Faculty of Business, Management and Economics, University of Latvia, Aspazijas blvd, 5, Riga, LV-1010, Latvia, aija.legzdina1@gmail.com

Daina SKILTERE, Faculty of Business, Management and Economics, University of Latvia, Aspazijas blvd, 5, Riga, LV-1010, Latvia, daina.skiltere@lu.lv

Jelena SALKOVSKA, Faculty of Business, Management and Economics, University of Latvia, Aspazijas blvd, 5, Riga, LV-1010, Latvia, jelena.salkovska@lu.lv

Girts BRASLINS, Faculty of Business, Management and Economics, University of Latvia, Aspazijas blvd, 5, Riga, LV-1010, Latvia, girts.braslins@inbox.lv

Vadims DANOVICS, Faculty of Business, Management and Economics, University of Latvia, Aspazijas blvd, 5, Riga, LV-1010, Latvia, vadims.danovics@lu.lv

Daina SAKTINA, Institute of Agricultural Resources and Economics, Liela street 2, Jelgava, LV-3001, Latvia, daina.saktina@arei.lv

Learning for product innovation in sustainable business within bioeconomy rapidly growing context has become one of the most important components of management educational models. Significant public support in EU countries goes to innovation training for companies. At the same time, many failed product innovations are entering the markets. Consumer market measurements indicate that $86 \%$ to $94 \%$ (Salkovska et al., 2018) of all innovations are commercially unsuccessful. Creating innovation is a resource intensive process. A high innovation failure rate is a significant loss not only to companies, but to the EU economy as a whole and its competitiveness. The high share of commercially unsuccessful innovations in markets points to areas for improvement in existing innovation education models. A better understanding of the components of successful product innovation will help to lead to improved business training models and therefore more productive bioeconomy and sustainability. The research analyses the components of commercially successful innovations. The most important components that determine the success of innovation are related to the consumption of innovation, the ideological values of innovation and the starting positions of innovation. The aim of the study is to identify the key components that make up commercially successful innovations so that they can be given in-depth attention in training models, thus enhancing the proportion of commercially successful innovations among organizations. The study uses the assessment of 63 innovation experts. Quantitative and qualitative methods of secondary and primary data processing have been used.

Keywords: innovation development, educational models, successful innovations, sustainability.

Abbreviations

- EU - European Union

- OECD - Organisation for Economic Co-operation and Development

- NPD - New product development

- TRIZ - Theory of Inventive Problem Solving

\section{INTRODUCTION}

Innovation is the engine of economic growth. The concept of innovation covers many aspects and is generally interpreted very broadly. The OECD (2005) defines innovation as an iterative process initiated by a new market perception and/or the possibility of a new service for technology-based intervention. The OECD emphasizes that innovations do not in themselves activate in the market, they need to be successfully implemented and adapted to the market. An invention becomes an innovation only when it provides economic value to the market. Innovation is also one of the most effective ways to increase the competitiveness of companies and ensure companies sustainability and ability to reach bioeconomy

Copyright (C) 2021 The Authors. Published by Vytautas Magnus University. This is an open-access article distributed under the terms of the Creative Commons Attribution License (CC BY 4.0), which permits unrestricted use, distribution, and reproduction in any medium, provided the original author and source are credited. 
goals (Braun, 2020; Boehlje et al., 2011; Gunday et al., 2011; Teece et al., 2010; Sloka et al., 2019; Cekuls et al., 2017). Innovations are important in all sectors, studies have demonstrated the growing share of innovative products in consumer markets and not only (Buligina et al., 2019; Kuzmina-Merlino et al., 2018). Even banks should seek to continue to diversify the products they provide with new and innovative solutions (Medrano et al., 2016; Saksonova, 2017). Improving competitiveness in the European Union through innovation is also the second of the five objectives of Horizon 2020. The aim of the Research is to promote an in-depth understanding of the factors of successful innovation creation to improve sustainability and bioeconomy related educational models on innovation creation in organizations. The object of Research is the components of commercially successful product innovation. The task of the Research is to identify the key components that shape commercially successful innovations, so that they can be included in training models, thus enhancing the growing share of commercially successful innovations among organizations in the context of sustainability and bioeconomy.

\section{RESEARCH METHODS}

Initially, the bioeconomy was politically stimulated by the depletion of fossil resources, but today the bioeconomy is driven by demand to provide products, processes and services in all sectors of the economy within a sustainable economic system (Braun, 2020).

The bioeconomy already fully incorporates the dynamics of market supply and demand, in which the main role is determined by innovation and the preference of the buyer between several choices (Casno, 2019). As highlighted by market research firm Euromonitor International, sustainable eating and the environmental cost of food have been identified as one of the most important themes in the food and beverage industries as well as consumer foodservice (Euromonitor International, 2021). For example, vegetarian-based "meat no meat" products of equivalent quality in Western Europe and North America face high and rapidly growing market competition, where product sustainability and planet-friendly origin are not the determining factors in a buyer's choice anymore. As a result, the bioeconomy faces new challenges, where sustainability will not be the determining factor in basic consumer preferences, and companies will have to find a new balance between market attractiveness and sustainability.

Innovation success is defined as the performance of innovation in the market, and the assessment of performance applies to both the organization that created the innovation and the consumer of the innovation (D'Este et al., 2015). The success of innovation is usually expressed as the turnover and its relative share in a comparable industry resulting from the introduction of innovation (Mothe, 2010). The success of innovation is also interpreted as a positive net cash flow (More, 2010). In turn, innovation failure is interpreted as a company's abandonment of innovation (Tranekjer, 2017). As the share of innovation in consumer markets increases, including the impact of sustainable innovations, share in the context of bioeconomy, both scientific and industrial research have identified many factors and components that influence innovation performance, namely its success in the market. The need for a strategy arises when it is possible to more precisely forecast development tendencies of industries and specific institutions (Saksonova, 2012). Influencing factors and components can be divided into macro-and micro-level impact zones and general and niche assessments. The macrolevel identifies the external ecosystem for innovation, the micro-level identifies the company's internal ecosystem. Research on macro-level innovation ecosystems is receiving a significant share of public administration's attention, and the main goal of improving the innovation ecosystem is the quantitative growth of regional, national and sectoral innovation in smart specialization, an increase of sustainability, growth of bioeconomy and high-productivity industries. The micro-level of innovation components and influencing factors are divided into general impact and specific components. The general components identify a wide range of possible innovation success factors at the organizational level and are generally divided into four main categories in the scientific literature: strategic, market, NPD development process and organizational culture components and factors. (Montoya-Veisa et al, 1994). The classification offers a wide range of variables and considers the product development process from inception to commercialization activities. The classifications of different scholars and authors internally between these strategic blocks differ and are arranged in different priority sequences, e.g., (Cooper et al., 1995) put forward innovation performance factors in order of importance: NPD process, NPD strategy and organizational culture, while other authors put forward other strategic combinations as a priority for successful innovation (Ernst, 2002).

Specialized micro-level assessments focus on the study of the internal components of a company's strategic blocks, which are related to the creation of innovations. These studies provide an in-depth assessment of the factors influencing successful innovation in one of the specific areas (Braslina, 2015). For example, in relation to the process of creating a new product, Altshuller G. created the algorithmic model TRIZ (Starovoytova, 2015). It is based on a detailed analysis of the components of inventions and innovations in patent databases and identifies the field of potential innovation inventions. TRIZ is one of the first models to mark product innovation as an algorithmic approach. Various innovation training models have been developed on the basis of TRIZ, which are also binding in postmodern marketplaces (Berdonosov, 2015; Greenberg, 2015). However, the TRIZ model does not address the potential success of innovation in terms of market value. The other matrix model (Batraga et al, 2018) distinguishes 34 components of market demand and identifies their connections in the creation of innovations. The model identifies the innovation components with the highest added value in the market, thus promoting the understanding of the algorithmic preconditions of innovation components for the creation of successful innovations. The scientific literature also distinguishes the components of innovation that determine the success of successful innovation (Batraga et al., 2019). 
With the rapidly growing role of the bioeconomy, scientists conceptualizing four types of the bioeconomy: substitute products, new innovations focused on biological processes, new organic products and new behaviors related to sustainability. These types are discussed in the scientific literature against the existing types of innovations, emphasizing the peculiarities of the bioeconomy (Bröring et al., 2020; Thormann et al., 2021).

There are identified phenomenons as well that small and medium-sized enterprises with limited access to technological innovations use references to bioeconomy and sustainability as another factor promoting product sales or the possibility to obtain financial support from the public sector (Saksonova, 2019). This is largely due to the income gap between urban and rural areas (Sloka, 2019).

Research methods: the methodological design of the research envisaged a 4-step pillars approach. Thematic discussions and in-depth interviews with experts were initially conducted to identify the key components of the commercial success of consumer innovations in the first and second phases. In the third phase, the identified components were subjected to a 48-expert materiality assessment. In the fourth stage of the Research, thematic discussions were conducted to validate the results obtained in the expert survey. The Research uses the assessment of 63 regional innovation experts according to the Quadruple Helix model approach. All experts are directly involved in the development of innovations and the Research was conducted from February 2019 to November 2020. Within the framework of the Research, a total of 16 in-depth interviews with experts, a survey of 48 experts and 4 thematic discussions. Quantitative and qualitative methods of secondary and primary data processing have been used.

\section{RESEARCH RESULTS}

In the thematic discussions in the study, the groups of components found in the scientific literature (Batraga et al, 2019) that determine successful product innovations were verified. Experts were asked to assess the importance of each component in relation to the potential success of innovation. Experts point out the consumption components of innovation (3.61 points) as the most important group influencing the success of the innovation market, following the ideologicalmission values of innovation (3.59 points) and the starting positions of innovation (3.57 points) (Table 1).

Table 1. Importance of the conceptual groups of product innovation components in the context of its market success

\begin{tabular}{llcc}
\hline No. & Importance of 4 conceptual groups of innovation constituting components & Assessment in points*1 & \multicolumn{2}{c}{ Coefficient of variation } \\
\cline { 3 - 4 } & & $\mathrm{X}$ & $\mathrm{CV}$ \\
\hline 1. & Innovation consumption components & 3.61 & $28.1 \%$ \\
2. & Innovation mission (ideological) value components & 3.59 & $30.0 \%$ \\
3. & Innovation start position (market entry) components & 3.57 & $32.0 \%$ \\
4. & Functional components of innovation & 3.17 & $28.7 \%$ \\
\hline
\end{tabular}

Source: 48 experts assessment evaluation (2020)

It is interesting that in the context of innovation success, the group of functional components of innovation (3.17 points) is graded as the less significant. This once again confirms the thesis of various economists about the irrational nature of consumer (Hill, 2012). The high evaluation of the ideological component indicates the importance of values, which is directly related to the concept of biocoenomics and sustainability.

From the group of consumption components, the six most important components for innovation success are related to innovation energy savings (4.00 points), consumption time savings (3.93 points), innovation opportunity to provide a new user experience (3.73 points), cost reduction (3.73 points), increased safety (3.67 points) and acquiring new or improved skills (3.60 points) (Table 2).

Table 2. Importance of the innovation consumption components in the context of its market success

\begin{tabular}{llcc}
\hline No. & Importance of the innovation consumption components & X & Coefficient of variation \\
\cline { 3 - 4 } & & 4.00 & $26.7 \%$ \\
\hline 1. & Energy savings & 3.93 & $20.3 \%$ \\
2. & Consumption time savings & 3.73 & $21.4 \%$ \\
3. & The experience of using new feelings for the consumer & 3.73 & $28.5 \%$ \\
4. & Consumer cost savings & 3.67 & $28.5 \%$ \\
5. & Improving consumer safety & 3.60 & $17.6 \%$ \\
6. & New or improved skills & & \\
\hline
\end{tabular}

Source: 48 experts assessment evaluation (2020)

Again, it is interesting to identify that the conceptual framework of sustainability and bioeconomy as energy savings outweighs other benefits of use. In relation to the starting positions of innovation, the most important components

\footnotetext{
$1 *$ Grade scale for Table 1 and Table 2: The rating is given in points. 4 - means that the group of components is significant and strongly influencing, 3 - the group of components is significant and influencing rather than insignificant and non-influential, 2 - the group of components is insignificant and little influencing rather than influencing and significant, 1 - the group of components is not significant.

$2 *$ Grade scale for Table 1 and Table 2: The rating is given in points. 4 - means that the group of components is significant and strongly influencing, 3 - the group of components is significant and influencing rather than insignificant and non-influential, 2 - the group of components is insignificant and little influencing rather than influencing and significant, 1 - the group of components is not significant.
} 
for the success of innovation are related to the company's investment in research and development (4.20 points), the scale of the innovation market (3.87 points) and advertising opportunities for innovation in the market (3.67 points) (Table 3$)$.

Table 3. Importance of the innovation start position (market entry) components in the context of its market success

\begin{tabular}{|c|c|c|c|}
\hline \multirow[t]{2}{*}{ No. } & \multirow[t]{2}{*}{$\begin{array}{l}\text { Importance of the innovation start position (market entry) } \\
\text { components }\end{array}$} & $\begin{array}{l}\text { Assessment in } \\
\text { points }\end{array}$ & Coefficient of variation \\
\hline & & $\mathrm{X}$ & $\mathrm{CV}$ \\
\hline 1. & The company's investment in research and development & 4.20 & $18.4 \%$ \\
\hline 2. & The scale and size of the innovation market & 3.87 & $19.2 \%$ \\
\hline 3. & Existence of advertising for innovation & 3.67 & $32.0 \%$ \\
\hline
\end{tabular}

Source: 48 experts assessment evaluation (2020)

Brand recognition (3.33 points), company scale (3.27 points) and company size (3.07 points) are relatively less important for innovation success from innovation market entry perspective. The evaluation of this section also shows a relatively high-value innovative approach to innovation development that requires investment from the company and is therefore related to the company's sustainability context.

The third most important group of innovation components is the ideological components of innovation - lifestyle and mission values. The three most important are related to the promotion of a healthy lifestyle (3.67 points), preservation/promotion of individual values (3.53 points) and preservation/promotion of natural values (3.53 points), which have equal assessment value (Table 4).

Table 4. Importance of innovation mission (ideological) value components in the context of its market success

\begin{tabular}{|c|c|c|c|}
\hline \multirow[t]{2}{*}{ No. } & \multirow{2}{*}{$\begin{array}{l}\text { Importance of the innovation mission (ideological) value } \\
\text { components }\end{array}$} & Assessment in points*3 & Coefficient of variation \\
\hline & & $\mathrm{X}$ & $\mathrm{CV}$ \\
\hline 1. & Promoting a healthy lifestyle & 3.67 & $30.3 \%$ \\
\hline 2. & Preservation / promotion of individual values & 3.53 & $35.3 \%$ \\
\hline 3. & Preservation / promotion of natural values & 3.53 & $38,6 \%$ \\
\hline
\end{tabular}

Source: 48 experts assessment evaluation (2020)

This assessment also shows a direct link between the three leading components in the field of sustainability and bio-economic innovation components related to the conservation of natural resources. Less important components of innovation are related to preservation/promotion of social values (3.27 points), preservation/promotion of cultural values (3.20 points), preservation/promotion of family values ( 2.73 points) and components supporting patriotic, religious and political values. (2.73 points). However, it should be noted here that the latter component may be assessed differently in regions where there is a threat to any of the latter values.

In relation to the functional components of the promise of innovation, experts see the least contribution to the commercial success of innovation. Although the impact of the group of components as a whole has been assessed as insignificant rather than essential for the success of the innovation, the individual components are significant. The highest ratings are for components for a healthier effect on the body (3.67 points), the promise of a new effective specific function of the product (3.67 points) and the addition or introduction of a new function of the product (3.47 points) (Table 5).

Table 5. Importance of the innovation funcional components in the context of it's market success.

\begin{tabular}{llcc}
\hline No. & Importance of the innovation funcional components & Assessment in points*4 & Coefficient of variation \\
\cline { 3 - 4 } & & 3,67 & CV \\
\hline 1. & The promise of a healthier effect on the body & 3,67 & $24,5 \%$ \\
2. & The promise of more efficient function & 3,47 & $19,7 \%$ \\
3. & New feature & $24,1 \%$ \\
\hline
\end{tabular}

Source: 48 experts assessment evaluation (2020)

Significant components in this functional components group are also a scientific discovery for innovation (3.33 points), enhanced or reduced exposure (3.27 points), new substance or material (3.20 points), combined or separated functions (3.20 points). Interestingly, for traditionally considered functional components of innovation as substances, new material composition (2.93 points), significantly reduced or increased product size (2.93 points), new product design (shape) (2.87 points), premium level price (2.80 points), new packaging ( 2.73 points) are the relatively lower impact to the success of the innovation.

\footnotetext{
$3 *$ Grade scale for Table 1 and Table 2: The rating is given in points. 4 - means that the component is significant and strongly influencing innovation success, 3 - the component is significant and influencing innovation success rather than insignificant and non-influential, 2 - the component is insignificant and little influencing innovation success rather than influencing and significant, 1 - the component is not significant to innovation success. $4 *$ Grade scale for Table 1 and Table 2: The rating is given in points. 4 - means that the component is significant and strongly influencing innovation success, 3 - the component is significant and influencing innovation success rather than insignificant and non-influential, 2 - the component is insignificant and little influencing innovation success rather than influencing and significant, 1 - the component is not significant to innovation success.
} 
The five most important components from all groups that are critical to the success of innovation are related to the innovation company's investment in research and development (4.20 points), innovation energy consumption savings (4.00 points), innovation consumption time savings (3.93 points), matter of innovation launch-entry market size (3.87 points) and innovation cost savings in the context of consumsion (3.73 points). Also in the overall assessment, the context of bioeconomy and sustainability emerges as a leader in the two leading components that determine the commercial success of innovation - investment in research and development and energy savings.

\section{CONCLUSION AND DISCUSSION}

The results of the research indicate that the components of the bioeconomy and sustainability play an important role in creating successful commercial innovations. For an entrepreneur whose motivation is to create a commercially successful and sustainable innovation supporting the increase of bioeconomy, the general EU modern innovation support ecosystem provides the impetus and favourable conditions to do so. Research indicates general guidelines at the microlevel provide an insight into the four priority groups that form the basis for successful innovation in a company and the importance of sustainability and bioeconomy components in there.

Entrepreneurship training models for sustainable innovations development are recommended to include in-depth training on specific key groups of innovation components that determine innovation success - innovation consumption components, innovation ideological-mission values, innovation functional components and innovation start (market entry) positions, additionally highlighting in the Research emphasized importance of sustainability and bioeconomy components. It is recommended to highlight special attention to the following areas of the innovation development educational models in the context of sustainability and bioeconomy - the company's investment in research and development, innovation energy consumption savings opportunities, innovation consumption time savings opportunities and target markets, where innovation is planned to launch.

Meanwhile, the further development of the bioeconomy and sustainable consumer innovation is no longer just a matter of policy and science, as in the previous decade. It has moved into market relationships where there are fierce competitions between companies and where companies can no longer rely solely on the components of sustainability and innovation to determine certain consumer preferences. One of the new challenges for public bioeconomy and sustainability is to provide an enabling environment for the development of innovative consumer bioeconomy products, while not driving them into unnecessary overconsumption and avoiding the mistakes of the conventional market economy. An equally important challenge is to reduce the unfair use of bioeconomy and sustainability slogans by companies in the production of innovative products, only to ensure the growing consumption of potentially unnecessary products to achieve the company's financial goals. Thus, those involved in the bioeconomy innovation ecosystem should promote a selfstabilizing innovation ecosystem that truly serves the goals of the bioeconomy, and not just the business for profit.

\section{REFERENCES}

1. Batraga, A., Salkovska, J., Braslina L., Kalkis, H., Skiltere, D., Legzdina A., Braslins G. 2019. Code of Breakthrough Innovations, Advances in Intelligent Systems and Computing. AHFE International Conference, pp. 345-351. https://doi.org/10.1007/978-3$\underline{030-11051-2 \_53}$

2. Batraga, A., Salkovska, J., Braslina, L., Legzdina, A., Kalkis, H. 2018. New Innovation Identification Approach Development Matrix. In Advances in Human Factors, Business Management and Society, Vol. 783, pp. 261 - 273. https://doi.org/10.1007/978$\underline{\text { 3-319-94709-9_26 }}$

3. Batraga, A., Salkovska, J., Braslina L., Kalkis, H., Skiltere, D., Legzdina A., Braslins G. 2019. Four Conceptual Perspectives of Innovation Components, Advances in Intelligent Systems and Computing Series. AHFE International Conference, Vol. 961, pp. 72-82. https://doi.org/10.1007/978-3-030-20154-8 7

4. Berdonosov, V. 2015. Concept of the TRIZ Evolutionary Approach in Education. Procedia Engineering, Vol. 131, pp. 721-730. https://doi.org/10.1016/j.proeng.2015.12.362

5. Boehlje, M., Roucan-Kane, M., Broring S. 2011. Future Agribusiness Challenges: Strategic Uncertainty, Innovation and Structural Change. International Food and Agribusiness Management Review, Vol. 14(5), pp. 53-82.

6. Braslina, L., Viksne, K., A. Upenieks, A., Batraga, A. 2015. Innovation Process Affecting Factors in Latvian Companies. Regional Formation and Development Studies, Journal of Social Sciences, Vol. 17(3), pp. 16-26. https://doi.org/10.15181/rfds.v16i3.1117

7. Braun, J. 2020. Bioeconomy and its set of innovations for sustainability. Industrial Biotechnology, 16(3), pp. 142-143. https://doi.org/10.1089/ind.2020.29210.jvb

8. Bröring, S., Laibach, N., Wustmans, M. 2020. Innovation types in the bioeconomy. Journal of Cleaner Production, Vol. 266. https://doi.org/10.1016/j.jclepro.2020.121939

9. Buligina, I., Sloka, B. 2019. Recent Development Trends of Vocational Education and Training in Latvia. Proceedings of International Scientific Conference "International Scientific Conference on The Impact of Industry 4.0 on Job Creation”, pp. 46-54.

10. Casno, L. K., Skiltere, D., Sloka, B. 2019. Factors that Motivate Latvian Consumers to Purchase Products and Services From Social Enterprises in Latvia: The Case of Socially Responsible Consumption. European Integration Studies, Vol. 13, pp. 90-99. https://doi.org/10.5755/j01.eis.0.13.23495

11. Cekuls, A., Malmane, E., Bluzmanis, J. 2017, The Impact of Remote Work Intensity on Perceived Work-Related Outcomes in ICT Sector in Latvia. New Challenges of Economic and Business Development - 2017: Digital Economy, pp. 96-107. 
12. Cooper, R.G. ,Kleinschmidt, E.J. 1995. Benchmarking the Firms Critical Success Factors in New Product Development. Journal of Product Innovation Management, Vol. 12, pp. 374-391. https://doi.org/10.1111/1540-5885.1250374

13. D'Este, P., Nabil., A., Olmos-Peñuela, J. 2016. Fostering Novelty While Reducing Failure: Balancing the Twin Challenges of Product Innovation. Technological Forecasting and Social Change, Vol. 113, pp. 280-292. https://doi.org/10.1016/j.techfore.2015.08.011

14. Ernst, H. 2002. Success Factors of New Product Development: a Review of the Empirical Literature. International Journal of Management Reviews, Vol. 4, pp. 1-40. https://doi.org/10.1111/1468-2370.00075

15. Euromonitor International. 2021. Sustainable Eating and the Environmental Cost of Food.

16. Gunday, G., Ulusoy, G., Kilıç, K., Alpkan, L. 2011. Effects of Innovation Types on Firm Performance. International Journal of Production Economics, Vol. 133(2), pp. 662-676. https://doi.org/10.1016/j.ijpe.2011.05.014

17. Greenberg, S. 2015. Development of Thinking Skills. Course: Teaching TRIZ in Academic Setting. Procedia Engineering, Vol. 131, pp. 219-223. https://doi.org/10.1016/j.proeng.2015.12.377

18. Hill, L. 2012. Adam Smith on Thumos and Irrational Economic'Man'. The European Journal of the History of Economic Thought, Vol. 19(1), pp. 1-22. https://doi.org/10.1080/09672561003632550

19. Joubert, J., Belle, J. 2012. Success Factors for Product and Service Innovation: A Critical Literature Review and Proposed Integrative Framework. Management Dynamics, Vol. 12, No. 2, pp. 1-26.

20. Kuzmina-Merlino, I., Saksonova, S. 2018. The Knowledge and Competencies Required for the Fintech Sector. New Challenges of Economic and Business Development - 2018: Productivity and Economic Growth, pp. 387-395.

21. Medrano, N., Olarte-Pascual, C. 2016. An Empirical Approach to Marketing Innovation in Small and Medium Retailers: An Application to the Spanish Sector. Contemporary Economics, Vol. 10, No. 3, pp. 205-216. https://doi.org/10.5709/ce.1897$\underline{9254.210}$

22. Moore, R. 2011. What is Success in Innovation? Ivey Business Journal, Roger Moore Issues.

23. Mothe, C., Uyen, N. 2010. The Link Between Non-Technological Innovations and Technological Innovation. European Journal of Innovation Management, Vol. 13(3), pp. 313-332. https://doi.org/10.1108/14601061011060148

24. Saksonova, S., Koḷeda, O. 2017. Evaluating the Interrelationship between Actions of Latvian Commercial Banks and Latvian Economic Growth. Procedia Engineering, Vol. 178, pp. 123-130. https://doi.org/10.1016/j.proeng.2017.01.075

25. Saksonova, S., Papiashvili, T. 2019. Small Business in a Small Country and the Role of Government. New Challenges of Economic and Business Development-2019: Incentives for Sustainable Economic Growth, pp. 719-727.

26. Saksonova, S., Solovjova, I. 2012. Some Quantitative Aspects of Stability Management Strategy in a Bank. Procedia - Social and Behavioral Sciences, Vol. 58, pp. 569-577. https://doi.org/10.1016/j.sbspro.2012.09.1034

27. Sloka, B., Jekabsone, I., Cipane, K., Vasina, S. A. 2019. Income Differences in Regions of Latvia - Problems and Challenges. European Integration Studies, Vol. 13, pp. 52-60. https://doi.org/10.5755/j01.eis.0.13.23562

28. Sloka, B., Kersule, L., Skruzkalne, I. 2019. Employee Motivators in Telecommunication Companies in Latvia. Proceedings of International Scientific Conference "International Scientific Conference on The Impact of Industry 4.0 on Job Creation", pp. 89-100.

29. Starovoytova, D. 2015. Theory of Inventive Problem Solving (TRIZ): His-Story. IJISET, Vol. 2, pp. 86-95.

30. Teece, D. 2010., Handbook of the Economics of Innovation, Chapter 16 - Technological Innovation and the Theory of the Firm: The Role of Enterprise-Level Knowledge, Complementarities, and (Dynamic) Capabilities. In Handbook of the Economics of Innovation, Vol. 1, pp. 679-730. https://doi.org/10.1016/S0169-7218(10)01016-6

31. Thormann, L., Neuling, U., Kaltschmitt, M. 2021. Opportunities and Challenges of the European Green Deal for the Chemical Industry: An Approach Measuring Innovations in Bioeconomy. Resources, Vol. 10(9). https://doi.org/10.3390/resources10090091

32. Tranekjer, T. 2017. Open Innovation: Effects From External Knowledge Sources on Abandoned Innovation Projects. Business Process Management Journal, Vol. 23(5), pp. 918-935. https://doi.org/10.1108/BPMJ-04-2016-0076 